\title{
As Virtudes de Constantino versus os Vícios de Maxêncio e Licínio segundo a História Eclesiástica de Eusébio de Cesareia (306-324)
}

\author{
The Virtues of Constantine versus the Vices of Maxentius and Licinius \\ according to the Ecclesiastical History of Eusebius of Caesarea
}

\begin{abstract}
Andréia Rosin Caprino Taborda ${ }^{1}$
${ }^{1}$ Doutoranda em História pela Universidade Federal do Paraná, bolsista CNPq. Mestrado em História (2017) e graduação em História - Licenciatura e Bacharelado (2014), ambos pela mesma instituição. Email: andreiarosincaprino@gmail.com.
\end{abstract}

Recebido em 11 de fevereiro de 2021; Aceito em 30 de maio de 2021.

DOI: $10.12957 /$ nearco.2021.57729

\section{Resumo}

No século IV d.C., Eusébio de Cesareia em sua História Eclesiástica vinculou as ações político-militares do imperador Constantino à vontade do Deus judaico-cristão. Neste trabalho analisaremos como o autor elaborou tais argumentos a fim de legitimar o poder do governante, através da atribuição de virtudes ao mesmo, em contraposição às características viciosas reservadas aos seus oponentes Maxêncio e Licínio.

Palavras-chave: História Eclesiástica; Virtudes e Vícios; Legitimidade imperial.

\begin{abstract}
In the fourth century A.D., Eusebius of Caesarea in his Ecclesiastical History linked the political-military actions of Emperor Constantine to the will of the Judeo-Christian God. In this paper we will analyze how the author elaborated such arguments in order to legitimize the power of the ruler, through the attribution of virtues to him, as opposed to the vicious characteristics reserved to his opponents Maxentius and Licinius.
\end{abstract}

Key-words: Ecclesiastical History; Virtues and Vices; Imperial legitimacy.

O presente tema está alinhado ao período denominado como Antiguidade Tardia, a qual se inicia com a desestruturação política e institucional do século Il e se estende até meados do século VIII. O governo do imperador Flávio Valério Constantino (306-337) está inserido em tal conjuntura. Esse personagem é aclamado Augusto pelos 
legionários de seu pai, Constâncio Cloro, em 306 na província da Britania. Ainda em regime de Tetrarquia, iniciado por Diocleciano em 293, a elevação de Constantino foi considerada usurpação ou ilegítima. Chama-nos a atenção que após décadas em que o poder imperial se encontrava fragmentado e/ou dividido entre várias lideranças, no ano de 324 Constantino tenha unificado o mundo romano sob sua exclusiva autoridade.

Isso se deu, acreditamos, porque Constantino buscou o apoio de todos os seus súditos. Imerso em um contexto em que o sustentáculo teórico do poder estava e continuava a ser transformado, sem, contudo, desvincular-se das ideias políticas anteriores, seu governo foi marcado pela associação de elementos tidos como conflitantes por parte da historiografia - paganismo e cristianismo, mas que acabam por se relacionar. Nosso estudo é centrado na análise da busca por legitimação imperial do governo de Constantino através do elemento cristão na obra História Eclesiástica, do autor e bispo (contemporâneo a ele) Eusébio de Cesareia (260/64-339).

A História Eclesiástica possui dez livros, os quais começam com citações do Antigo Testamento sobre prenúncios da vinda de Jesus Cristo à Terra, a descrição da sua vida aqui, perpassa os acontecimentos eclesiásticos dos três primeiros séculos, abordando a sucessão dos bispos nas sedes episcopais, as perseguições aos cristãos, os martírios, as heresias, os governos imperiais, até findar com a vitória de Constantino sobre seu último oponente, o imperador Licínio, no ano de 324 . O nosso recorte se centra do ano 306, quando Eusébio narra a substituição do governo de Constâncio pelo de Constantino, na Britania (livro oitavo), até quando este se torna Augustus único na política imperial romana em 324 (livro décimo).

O cristianismo é entendido por Eusébio de Cesareia na História Eclesiástica como uma espécie de continuador da religião hebraica, no sentido de nela ter se embasado grandemente para formar seus credos e paradigmas. Assim, nem o cristianismo nem outro pensamento qualquer eram totalmente "puros", pois se fundamentavam em ideias anteriores, fossem para concordar com elas ou confrontá-las.

O processo de reinado político-administrativo de Constantino é interpretado pelo bispo de Cesareia como uma história conduzida pelo próprio Deus, o qual esteve sempre presente com o imperador (segundo ele), ajudando-o a vencer os inimigos do 
cristianismo. Os conflitos militar-religiosos com os quais Constantino se envolveu foram, primeiro em relação a Maxêncio (306-312) no ocidente, derrotado em 312, e depois, em relação a Licínio (308-324), no oriente, vencido em 324. Por meio de argumentos que engrandecem ou diminuem moralmente um líder - virtudes e vícios, Eusébio representa os bons e os maus governantes. Os bons condutores estão, obviamente, vinculados às qualidades cristãs, e os maus são destituídos delas. Entendemos que o modo como a História Eclesiástica constrói a legitimidade de Constantino enquanto líder imperial é expondo suas virtudes, e contrapondo-as, explicitamente ou não, aos vícios dos seus maiores oponentes.

Mais do que uma nomeação definida, as virtudes consistiam em uma ideia ou conceito que almejava imprimir determinada visão e valores de um governante aos seus conterrâneos, para engrandecê-lo; o mesmo pode ser dito a respeito dos vícios, mas com a intenção de denegrir o líder/governante. Para além disso, o historiador Manuel Rodríguez Gervás alega que "O estudo das virtudes permite aproximarmo-nos não apenas da concepção do poder imperial, como também nos ajuda a compreender a conjuntura política em que estavam imersos [...] os imperadores [...] (RODRÍGUEZ GERVÁS: 1991, P.77)53. A respeito da finalidade e função das virtudes, assinala o autor:

Os suportes mais frequentemente empregados para difundir esta propaganda são os discursos de exaltação, pronunciados em ocasiões mencionadas, as inscrições em edifícios públicos, especialmente Arcos de Triunfo e as moedas, concretamente a lenda dos reversos. As "virtudes" teriam, pois, a função de elaborar, formalizar e intensificar a imagem imperial com o objetivo básico de criar uma estrutura política unitária. (RODRÍGUEZ GERVÁS, 1991, P.77).54

Eusébio de Cesareia, quando escreveu o final do livro oitavo, os livros nono e décimo da História Eclesiástica, vivia a instabilidade política do mundo romano, a

53 “El estudio de las 'virtudes' permite acercarnos no sólo a la concepción del poder imperial, sino también nos ayuda a comprender la coyuntura política en la que están inmersos [...] los emperadores $[\ldots]^{\prime \prime}$.

54 “Los soportes más frecuentemente empleados para difundir esta propaganda son los discursos de alabanza, pronunciados en ocasiones señaladas, las inscripciones en edificios públicos, especialmente Arcos de Triunfo y las monedas, concretamente la leyenda de los reversos. Las "virtudes" tenían, pués, la función de elaborar, formalizar e intensificar la imagen imperial con el objetivo básico de crear una estructura política unitaria". 
existência do poder imperial descentralizado, as divisões territoriais do Império e as usurpações e tiranias. É natural que, como bispo de uma importante província romana e enquanto um homem erudito pensasse a respeito da "instituição política maior" que regia a ele e a seus pares, além das questões religiosas, que lhe eram essenciais.

Ora, Constantino fazia parte dessa "alta política" e estava envolvido com o cristianismo, criando leis e aplicando-as em favor dos cristãos. Contudo ele não era o único imperador, nem o maior deles, e enfrentava constantes oposições ao seu exercício do poder. Portanto, fazia-se necessário demonstrar a grandiosidade das suas ações e a necessidade de tornar seu governo mais forte e unificado. Pensamos que essas ideias nortearam Eusébio a integrar no seu relato as virtudes atribuídas a Constantino, com a finalidade de legitimá-lo em detrimento dos oponentes. Assim, o bispo empreende na História Eclesiástica a distribuição de virtudes ao imperador Constantino, em paralelo aos vícios que incumbiu aos seus adversários, Maxêncio e Licínio.

\section{Constantino e Maxêncio}

Sobre os conflitos político-militares ocorridos entre os governantes Constantino e Maxêncio no início da década de 310, tendo como principal disputa o poderio sobre a cidade de Roma, Eusébio de Cesareia afirma o seguinte:

\footnotetext{
Constantino foi o primeiro dos dois [ele e Licínio] - primeiro também em honra e dignidade imperiais - que mostrou moderação com os oprimidos pelos tiranos em Roma. Depois de invocar como aliado em suas orações ao Deus do céu e a seu Verbo, e ainda ao próprio Salvador de todos, Jesus Cristo, avançou com todo seu exército, tentando alcançar para os romanos sua liberdade ancestral. Maxêncio, sabemos, confiava mais nos artifícios da magia do que na benevolência dos súditos, e na verdade não se atrevia a dar um passo fora das portas da cidade, apesar de que, com a multidão de hoplitas e com as inumeráveis companhias de legionários, cobria todo lugar, toda região e toda cidade, todas as que tinha escravizadas, em torno de Roma e em toda a Itália. O imperador, aferrado à aliança de Deus, ataca o primeiro, o segundo e o terceiro exército do tirano, e depois de vencê-los a todos com facilidade, avança o mais que pode pela Itália até muito perto de Roma. (EUSÉBIO. H.E., IX, IX, II-III) 55
}

55 Os hoplitas eram os soldados da infantaria. 
A vitória constantiniana sobre o "tirano" Maxêncio é associada na História Eclesiástica ao triunfo de Moisés, quando guiou o povo de Israel para fora das terras egípcias e para longe da opressão do faraó, conforme consta no Antigo Testamento.

\begin{abstract}
Da mesma forma que, nos tempos de Moisés e da antiga piedosa nação dos hebreus, precipitou no mar os carros do faraó e seu exército, a flor de seus cavaleiros e capitães; o mar Vermelho os tragou, o mar os cobriu, assim também Maxêncio e os hoplitas e lanceiros de sua escolta afundaram na profundeza como uma pedra quando, dando as costas ao exército que vinha da parte de Deus com Constantino, atravessava o rio que Ihe cortava o caminho e que ele mesmo havia unido e bem pontoneado com barcas, construindo assim uma máquina de destruição contra si mesmo. Dele se poderia dizer: cavou um fosso e tirou-lhe a terra; e cairá na vala que fez. Seu trabalho se voltará contra sua cabeça, e sua injustiça recairá sobre sua moleira. Assim pois, desfeita a ponte estendida sobre o rio, a passagem afunda e as barcas se precipitam de um golpe no abismo com todos seus homens; e ele mesmo em primeiro, o homem mais ímpio, e logo os escudeiros que o rodeavam afundaram como chumbo nas águas impetuosas, como já predisse o oráculo divino. (EUSÉBIO. H.E., IX, IX,V-VII)
\end{abstract}

Constantino aparece como salvador e libertador do populus romano, sendo associado ao profeta e líder do povo hebreu, Moisés. Vemos no excerto eusebiano um motivo pelo qual Constantino combatera Maxêncio e seu exército: a tirania, injustiça e opressão deste sobre Roma. O "imperador cristão" teria tido compaixão da cidade e de seus moradores, o que o levou a salvá-los, tendo como aliado o próprio Deus e Jesus Cristo. Vislumbra-se a razão preponderante para esta "vitória santa" no olhar do bispo: as qualidades piedosas e misericordiosas de Constantino. Não nos parece que Eusébio faça qualquer referência à vontade de Constantino em deter a autoridade como imperator único, para o que seria necessário afastar e/ou eliminar seus oponentes.

A elaboração teórica que Eusébio faz quando compara Constantino a Moisés, em meio à vitória do imperador sobre o rival Maxêncio, está presente também em outra obra eusebiana, a Vida de Constantino:

Como nos tempos de Moisés e do piedoso povo dos hebreus "[o Senhor] lançou no mar os carros de Faraó e o seu exército, e os seus capitães afogaram-se no mar Vermelho", não de outra forma Maxêncio e a corte de hoplitas e doríforos "se afundaram no mar como se fossem pedras", quando, de costas para o poder divino que sustentava Constantino, atravessava o rio que estava em frente à direção da marcha. O mesmo havia unido as margens do rio através de barcos, e construindo uma ponte infalível, terminou por unir 
um artefato catastrófico para si, sendo assim que acreditava capturar com ele o amigo de Deus. (EUSÉBIO. H.E., I, XXXVIII,II ) 56

Após vencer Maxêncio e adentrar triunfalmente em Roma, Constantino aparece como o libertador, salvador e benfeitor da cidade:

[...] de forma que, se não com palavras, como é natural, mas pelo menos com as obras, os que com a graça de Deus haviam se alçado à vitória, poderiam junto com os seguidores do grande servo Moisés entoar o mesmo hino que contra o ímpio tirano de então e dizer: Cantemos ao Senhor, porque gloriosamente cobriu-se de glória. Cavalo e cavaleiro lançou ao mar. Minha ajuda e minha proteção, o Senhor; se fez meu salvador; e Quem como tu entre os deuses, Senhor? Quem como tu, glorificado nos santos, admirável na glória, operador de maravilhas! Estas e muitas outras coisas parecidas com estas cantou Constantino com suas obras ao Deus supremo, causa de sua vitória, e entrou em triunfo em Roma, enquanto todos em massa, com suas crianças e suas mulheres, os senadores e altos dignitários, e todo o povo romano, recebiam-no com os olhos brilhantes, de todo coração, como a um libertador, salvador e benfeitor, em meio a vivas e a uma alegria insaciável. (EUSÉBIO. H.E., I,X, IX, VIII-IX) 57

Constantino é visto por Eusébio de Cesareia como piedoso, benevolente, sábio, digno, devoto e corajoso, enquanto Maxêncio é apresentado como um ímpio, tirano, maldoso e covarde. Eusébio opõe os dois governantes, e pela fidelidade e reverência atribuídas ao primeiro em relação a Deus e a falta destas qualidades ao segundo, quando incorre a batalha entre ambos, é Constantino quem recebe a vitória e conquista a cidade de Roma, até então dominada e oprimida por Maxêncio.

\section{Constantino e Licínio}

Ao adentrarmos o livro $\mathrm{X}$ da História eusebiana, vemos a referência às declarações sobre a paz delegada por Deus aos homens após a derrota de imperadores

56 “Como en los tiempos de Moisés y del piadoso pueblo de los hebreos "arrojó al mar los carros del Faraón juntamente con su ejército y anegó en el mar Rojo a la flor y nata de su escolta de encopetados caballeros", no de otra manera Majencio y el cortejo de hoplitas y doríforos "se hundieron en el mar como si fuesen piedras", cuando, dando la espalda a la potencia divina que asistía a Constantino, atravesaba el río que está de cara a la dirección de la marcha. Él mismo había unido las riberas del río mediante barcas, y construyendo un puente a toda prueba, terminó por ensamblar un artilugio catastrófico para sí mismo, siendo así que confiaba atrapar con él al amigo de Dios".

57 Em itálico, referência ao livro de Êxodo: 15:1-2 e 15:11. 
inimigos do cristianismo, a restauração de igrejas, as dedicações e consagrações de igrejas recém-construídas (X, I-IV), e ações de liberdade e favorecimento à religião cristã por parte dos imperadores em regime de Diarquia, Constantino e Licínio, expressos pelo Edito de Milão de 313 (X,V, I-XIV). Além disso, são citados e copiados outros mandamentos e decisões imperiais de Constantino em favor da igreja e dos bispos, como benefícios e concessões para a igreja e a convocação de sínodos com o objetivo de dissipar divisões entre os bispos (X, V, XV-XIV; VI, VII).

Entretanto, na reta final do livro décimo, Eusébio relata uma mudança no rumo político do Império. Licínio "perverteu-se" pela inveja que sentia do companheiro Constantino e passou a persegui-lo:

\begin{abstract}
Mas nem a inveja inimiga do bem, nem o demônio, amante do mal, podiam suportar a contemplação do que viam; como tampouco para Licínio o sucedido aos tiranos anteriormente mencionados foi suficiente para uma atitude prudente. Ele que havia sido considerado digno de um governo bem próspero, digno da honra do segundo posto depois do grande imperador Constantino e digno de afinidade e parentesco do mais alto grau, ia se afastando da imitação dos bons e, em troca, copiava a perversidade e malícia dos ímpios tiranos. E ainda que tivesse visto com seus próprios olhos o final catastrófico destes, preferiu segui-los em seu sentimento a permanecer na amizade e boa disposição de seu superior. Presa da inveja para com o benfeitor universal, provoca contra ele uma guerra execrável e terrível, sem respeito pelas leis da natureza e sem trazer à mente a memória dos juramentos, do sangue e dos pactos. (EUSÉBIO. H.E., X, VIII, II-III)
\end{abstract}

Licínio é descrito como um traidor à ótima condição que lhe propiciou o benevolente Constantino, como o "segundo após o imperador" e pertencente à família. O fim catastrófico dos antigos “inimigos do cristianismo" também não lhe serviu de lição, sendo que Licínio tornava-se um deles. No trecho abaixo, Eusébio opõe a postura benevolente de Constantino à maldade e traição de Licínio; este, por meio de conspiração, fingimento e astúcia, planejava destruir aquele:

De fato, que sinais de verdadeira benevolência não the havia outorgado o boníssimo imperador! Não lhe regateou seu parentesco nem lhe negou esplêndidas núpcias com sua irmã, antes até, considerou-o digno de compartilhar sua nobreza, que vinha de seus pais, e seu sangue imperial ancestral, e também havia-lhe proporcionado poder desfrutar do governo supremo como cunhado e co-imperador, posto que havia-lhe dado a graça de uma parte não menor de povos sujeitos a Roma, para que os governasse e 
administrasse. Mas ele, por sua vez, agia contrariamente a isto e cada dia imaginava intrigas contra seu superior e imaginava todo gênero de conspirações, como se respondesse com males a seu benfeitor. Assim é que, em primeiro lugar, tratava de ocultar seus preparativos fingindo ser amigo, e aplicando-se à astúcia e ao engano, esperava alcançar com toda facilidade o resultado apetecido. (EUSÉBIO. H.E., X,VIII, IV-V)

No entanto, de maneira radicalmente oposta ao "perverso" Licínio, Constantino possuía a benção de Deus para "guiá-lo na jornada contra o mal":

Mas deve-se saber que aquele tinha Deus como amigo, protetor e guardião, que, trazendo à luz as conspirações urdidas contra ele secretamente e nas sombras, ia desbaratando-as. Tão grande força e virtude tem a arma da piedade para rechaçar os inimigos e preservar a própria salvação! Guarnecido com ela, nosso imperador, amado de Deus, ia esquivando as conspirações do infame astuto. (EUSÉBIO. H.E., $\mathrm{X}, \mathrm{VIII}, \mathrm{VI})$

Licínio, percebendo que seus planos malignos não vingavam, segundo Eusébio, decidiu manifestar claramente suas intenções de guerra contra o "amado de Deus" e, para além disso, contra o próprio Deus:

\begin{abstract}
Este, por sua parte, quando viu que seus preparativos ocultos de modo algum andavam conforme seus desígnios, já que Deus ia manifestando a seu amado imperador todo engano e toda maldade, e não podendo já dissimular por mais tempo, declarou abertamente a guerra. Decidido, efetivamente, a fazer a guerra contra Constantino, apressava-se já a formar suas tropas também contra o Deus do universo, a quem sabia que aquele honrava, e logo pôs-se a atacar - moderada e silenciosamente a princípio - seus próprios súditos adoradores de Deus, que jamais haviam causado o mínimo incômodo a seu governo. E agia assim porque sua maldade inata o forçava a uma terrível cegueira. Ocorre que ele não tinha ante os olhos a memória dos que haviam perseguido os cristãos antes dele, nem sequer a daqueles de quem ele mesmo havia sido instrumento de ruína e de castigo pelas impiedades em que haviam tomado parte. Pelo contrário, voltando as costas a um pensamento prudente, e mais, em termos exatos, transtornado pela loucura, tinha decidido fazer a guerra ao próprio Deus, como protetor de Constantino, em vez de ao protegido. (EUSÉBIO. H.E., X, VIII, VII-IX)
\end{abstract}

A História Eclesiástica retrata que o "tirano" e "ímpio" Licínio empreendeu atitudes maldosas contra pessoas inocentes, violou a tradição e leis romanas, inventou mentiras, extorquiu outros povos, abusou sexualmente de mulheres e levou outros 
homens a fazerem o mesmo, destruiu e fechou igrejas, entre tantas outras iniquidades, de acordo com o autor:

Em primeiro lugar expulsou de sua própria casa todos os que eram cristãos, com o que o desgraçado privou a si mesmo da oração destes por ele, oração que costumavam fazer por todos, segundo ensinamento ancestral; mas logo foi dando ordens para que em cada cidade se separasse e degradasse os soldados que não escolhessem sacrificar aos demônios. [...] Que necessidade há de recordar uma por uma e sucessivamente as coisas que este inimigo de Deus perpetrou e como sendo o maior violador das leis inventou leis ilegais? [...] Que necessidade temos de enumerar detalhadamente suas inovações acerca das núpcias ou suas disposições revolucionárias a respeito dos que deixam esta vida? Atreveu-se a abolir as antigas leis romanas, reta e sabiamente estabelecidas, e introduziu no lugar delas algumas leis bárbaras e incivilizadas, verdadeiramente ilegais e contra as leis. Inventava também inumeráveis acusações contra as nações submetidas, toda classe de extorsões de ouro e prata, novos cadastros e lucrativas multas a homens que já não estavam nos campos, mas que tinham morrido há tempo. E que classe de desterros inventou ainda o inimigo dos homens contra pessoas que nenhum dano tinham lhe causado? $E$ as detenções de homens nobres e notáveis dos quais separava suas legítimas esposas e as entregava a alguns criados lascivos para que as ultrajassem com suas torpezas? E ele mesmo, um velhote, quantas mulheres casadas e quantas donzelas não vexou para satisfazer a paixão desenfreada de sua alma? Que necessidade temos de alongar a conta, se o excesso de suas últimas maldades deixou as primeiras pequenas e reduzidas a quase nada? Certo é que, no cúmulo de sua loucura, procedeu contra os bispos. [...] O certo é que o que foi realizado em torno de Amasia e as demais cidades do Ponto superou a todo excesso de crueldade. Ali, das igrejas de Deus, algumas foram novamente arrasadas por completo, e outras foram fechadas para que ninguém fosse a elas segundo o costume nem oferecessem a Deus os cultos devidos. (EUSÉBIO. H.E., X, VIII, X-XV)

\section{O "malfeitor" é descrito como aquele que pretendia agravar a situação dos}

cristãos ainda mais, planejando implantar novamente a perseguição, não fosse a presciência de Deus e sua intervenção no caminho trilhado por aquele governante. Para impedir o cumprimento das "maquinações" de Licínio contra o povo, Deus teria orientado o servo Constantino, o "salvador", a enfrentar o adversário dos homens:

Ante estes fatos reiniciaram-se as fugas dos homens piedosos, e novamente os campos, os vales solitários e os montes começaram a acolher os servos de Cristo. E como desta maneira o ímpio tinha êxito nestas medidas, chegou mesmo a conceber a idéia de ressuscitar a perseguição contra todos. Seu pensamento se reafirmava e nada o impedia de pô-lo em ação, se o Deus que luta em favor das almas que lhe pertencem, prevendo o que sucederia, não tivesse rapidamente feito brilhar, como em trevas profundas e noite escuríssima, uma grande luminária e ao mesmo tempo um salvador para 
todos: seu servo Constantino, a quem levou pela mão para esta obra com braço poderoso. (EUSÉBIO. H.E., X, VIII, XVIII-XIX)

Foi então que Constantino obteve a vitória:

A este, por conseguinte, foi que Deus outorgou desde cima, como fruto digno de sua piedade, o troféu da vitória contra os ímpios. Em troca, precipitou o criminoso com todos seus conselheiros e amigos aos pés de Constantino. Efetivamente, tendo aquele feito avançar seus atos até extremos de loucura, o imperador amigo de Deus concluiu que já era insuportável. Fazendo seu cálculo prudente e somando a sua humanidade a firmeza do juiz, decide acudir em socorro dos que sofriam sob o tirano. Desembaraçou-se de alguns breves contratempos e pôs-se em movimento para recobrar a maior parte do gênero humano. Até então, efetivamente, havia utilizado com ele somente a humanidade, e havia-se compadecido de quem não era digno de compaixão, sem proveito nenhum, já que o outro não se afastava de sua maldade, antes até, aumentava ainda mais sua raiva contra as nações submetidas e já não deixava nenhuma esperança de salvação para os maltratados, tiranizados como estavam por uma fera espantosa. (EUSÉBIO. H.E., X, IX, I-III)

O excerto demonstra que Constantino não teria lutado Licínio simplesmente por vontade de fazê-lo, já que era provido de humanidade e até então agira com compaixão para com o "malfeitor". Percebendo ser a situação insuportável, decidiu operar em defesa dos oprimidos. Aqui, Eusébio enfatiza a virtude da humanitas58 no caráter e formação de Constantino. O sentido de humanitas que parece predominar na História Eclesiástica quando se refere a Constantino em relação a Licínio é o de "compaixão", mas nem por isso permitiu o "bom imperador" que aquele agisse livremente a fim de acabar com vidas inocentes e fazer sofrer tantos outros indivíduos. Aos olhos de Eusébio, o combate e consequente vitória de Constantino sobre Licínio talvez fosse até

58 Sobre a humanitas, Maria Helena da Rocha Pereira afirma: "A palavra donde deriva 'humanidade' tem uma história mais que todas atraente e rica de significado. Efectivamente, humanitas deriva de humanus, que por sua vez está relacionado xom homo ('o homem') e humus ('a terra'). [...] Temos, portanto, com muita probabilidade, a noção de 'ser terreno' ligado à de modos de comportamento que lhe são próprios, e esta à de um conjunto mais vasto que se transforma num conceito englobante - o de humanitas. Mas humanitas não é para os antigos, senão tardiamente, o conjunto de seres humanos. É também a natureza e sentimento dos homens [...] humanitas é já civilidade, que se opõe à crueldade primitiva, desconhecedora do direito. Tal oposição repete-se com frequência, em contextos em que a humanitas se associa intimamente a comitas ('cordialidade'), mansuetudo ('doçura') e [...] clementia [...] Cícero emprega frequentemente humanitas em acumulação, por vezes tautológica, com doctrina, litterae e studia. [...] Em autores posteriores, a humanitas será sobretudo a qualidade mista de saber, polimento, receptividade, simpatia, que aproxima os homens [...]" Ideias morais e políticas dos romanos, In: Estudos de História da cultura clássica. Lisboa: Fundação Calouste Gulbenkian, 1967, p. 415-421. 
mesmo um indicativo da humanitas constantiniana para com os desfavorecidos e sofredores dos males sob a tirania.

\section{Considerações finais}

Em meio ao contexto de instabilidade política, pensamos que Constantino buscou legitimidade por meio do cristianismo, sendo que o mesmo gradativamente recebeu caráter institucional em detrimento da conotação supersticiosa que possuía anteriormente. É aceitável a ideia de uma projeção desta religião através das ações políticas do imperador; para constatarmos isso, porém, não é necessária a afirmação de uma conversão pessoal do governante à religião cristã. Acreditamos que a cultura política ditou mais as diretrizes assumidas em seu reinado que suas opções de crença, o que também não pode ser enquadrado em um pensamento final, já que a função real de Constantino era a de um imperador que necessitava fazer frente às oposições e ameaças ao seu poder, buscando todas as formas cabíveis para fortalecer e fundamentar sua autoridade.

Pensamos que não apenas ele, mas também Licínio, Maxêncio e outros possivelmente almejavam à governança una. O combate entre os líderes imperiais foi, em grande parte, resultado da instabilidade político-administrativa presente na década de 310 (e não apenas nela), a qual de certa forma instigou cada um deles a buscar a conquista de determinadas áreas territoriais e o poderio imperial sobre elas e seu populus.

A legitimidade de Constantino é construída na História Eclesiástica principalmente nos momentos da trajetória do governante quando luta e vence seus maiores inimigos: Maxêncio e Licínio. No momento político-militar conturbado que o imperador vivia, as vitórias não eram legítimas em si mesmas, era necessário o esforço em afirmá-las. Algo distinto dos demais imperatores que ocorreu com Constantino foi a sua associação com o cristianismo. Não podemos mensurar com precisão como tal vínculo aconteceu e a qual nível chegou, isso nem mesmo é o nosso objetivo. Entretanto sabemos que, independentemente de possuir uma crença pessoal na fé cristã, 
Constantino foi declarado piedoso e benevolente para com os fiéis do Deus judaicocristão. Um dos grandes responsáveis por esse ideal foi o bispo Eusébio.

Além da importância dos argumentos eusebianos no que se refere ao governante a fim de legitimá-lo, a própria obra constitui um "estatuto" de afirmação do poder de Constantino. Dizemos isso porque a História Eclesiástica é um trabalho de grande fôlego, que abrange três séculos da história da comunidade cristã, inclusive excedendo essa temporalidade, pois remonta às profecias do Antigo Testamento.

\section{Referências Bibliográficas}

\section{Documentação}

CESAREIA, Eusébio de. História Eclesiástica. São Paulo: Novo Século, 2002.

CESAREIA, Eusébio de. Vida de Constantino. Gredos: Madrid, 1994.

\section{Bibliografia}

ALTANER, B; STUIBER, A. Patrologia: vida, obras e doutrina dos Padres da Igreja. São Paulo: Paulinas, 1988, p.229-230.

BLÁZQUEZ MARTíNEZ, José Maria. El cristianismo, religión oficial. Historia 16, año XXI, 1997, p.56-65.

BRAVO, Gonzalo. Historia del mundo antiguo, Una introducción crítica. Madrid: Alianza Editorial, 1998.

CAMERON, Averil. II potere di Costantino, Dimensioni e limiti del potere imperiale, In: Constantino I. Enciclopédia Constantiniana. Sulla Figura e l'immagine dell'imperatore del cosiddeto Edditto di Milano. 313-2013. Volume Primo. Intituto della Enciclopedia Italiana. Roma, 2013.

DANIÉLOU, Jean; MARROU, Henri. Nova História da Igreja. Petrópolis: Vozes, 1973, v.I. 
FIORETTI, Susana. La figura del obispo latino y su influencia en la tardía antigüedad. In: Semanas de Estudios Romanos. Vol. XI. Instituto de História da Pontifícia Universidade Católica de Valparaíso, 2002, p. 229-241.

FRAZÃO, Andréia Cristina. O nascimento da Historiografia cristã no IV século. Calíope. Presença Clássica, Rio de Janeiro, 1993, n. 9.

FRIGHETTO, Renan. Algunas consideraciones sobre las construcciones teóricas de la centralización del poder político en la Antigüedad Tardia: cristianismo, tradición y poder imperial, In: História: Entre el pesimismo y la esperanza. Viña del Mar: Altazor, 2007.

FRIGHETTO, Renan. Da teoria à prática política: o exercício do poder na Antiguidade Tardia. Revista História Helikon, v.2, no 2, Curitiba, Pontifícia Universidade Católica do Paraná, p.16-36.

GONÇALVES, Ana Teresa Marques. Os Severos e a Anarquia Militar. In: Repensando o Império Romano - Perspectiva socioeconômica, política e cultural. Vitória: Edufes, 2006, p.175-191.

HOLLOWAY, R. Ross. Constantine and the Christians, In: Constantine and Rome. Michigan: Sheridan Books, 2004.

MOMIGLIANO, Arnaldo. As origens da historiografia eclesiástica, In: As raízes clássicas da historiografia moderna. Bauru: Edusc, 2004.

PEREIRA, Maria Helena da Rocha. Ideias morais e políticas dos romanos, In: Estudos de História da cultura clássica. Lisboa: Fundação Calouste Gulbenkian, 1967.

RODRÍGUEZ GERVÁS, Manuel José. La justificación del poder imperial: las "virtudes". In: Propaganda política y opinión pública en los panegíricos latinos del bajo imperio. Salamanca: Universidade de Salamanca, 1991.

RODRÍGUEZ GERVÁS, Manuel José. Las virtudes del emperador Constantino. Revista Gerión. Madrid: n.2-3, 1984-85, (239-247).

SÁNCHEZ SALOR, Eustaquio. Historiografía latino-cristiana: princípios, contenido, forma. Roma: L'erma di Bretschneider, 2006. 
SILVA, Gilvan Ventura da; Mendes, Norma Musco. Diocleciano e Constantino: a construção do DOMINATO, In: Repensando o Império Romano - Perspectiva socioeconômica, política e cultural. Vitória: Edufes, 2006.Stadler,

STADLER, Thiago David. O Império Romano em cartas - Glórias romanas em papel e tinta, Plínio, o Jovem e Trajano 98/113 d.C. Curitiba: Juruá, 2013.

VEYNE, Paul. Quando o nosso mundo se tornou cristão. Texto \& Grafia: Lisboa, 2009. 